\title{
A Música Popular Brasileira repensa identidade e nação
}

\section{Identidade nacional: novos parâmetros de análise}

\section{RESUMO}

O objetivo desse artigo é abordar o universo da música massiva no Brasil, focando a discussão na Música Popular Brasileira e o papel que seus criadores, a partir dos anos 60, têm na reflexão e na construção de novos parâmetros para se pensar identidade nacional e o Brasil enquanto nação. O Brasil tem na produção musical ligada à canção popular papel decisivo na gênese de novas identidades nacionais híbridas; não mais fixas, nem essencializadas, mas marcadas pela articulação do "próprio" e do "alheio". Seus criadores auxiliam a quebrar as barreiras asfixiantes criadas por nacionalistas empedernidos, mas sem cair na também asfixiante aceitação cega daquilo que é produzido e entendido na metrópole como o melhor.

\section{PALAVRAS-CHAVE}

- MPB

- Tropicália

- identidade nacional

\section{ABSTRACT}

The aim of this work is to analyse the importance of the role played by pop song musicians on the imaginary of the Post-Sixties generation in Brazil, for has helped in the building of a space of expression and manifestations such as had never previously existed in such moulds before. $M P B$ holds a means of artistic creation and a kind of authorship well inserted into this new world context where the frontiers have been erased and identities have been blended. Brazilian popular musicians can serve as excellent sources for researchers interested in learning about the transformation of national identity and the idea of nation. Theirs creations retains the marks of the transformations undergone by their Brazilian society, and have recreated such transformations into peculiar aesthetical forms of artistic expression.

\section{KEY WORDS}

- Brazilian popular music

- Tropicália

- national identity

\section{Marildo José Nercolini UFF}

A identidade nacional não é mais vista enquanto atributo natural adquirido pelo sujeito por pertencer à determinada nação. Não nascemos com uma identidade nacional, ela é formada e transformada de acordo com as representações que vamos adquirindo e criando. Nação é, resgatando Benedict Anderson (1989), uma comunidade imaginada com suas instituições culturais, seus símbolos e representações, com seu modo de construir sentidos e, portanto, de construir identidades.

Os limites nacionais encontram-se imprecisos e móveis. Hoje se torna ilusório pensarmos em termos de nação a partir de pressupostos como o de um povo puro, com uma história homogênea construída pelos heróis nacionais. Se não há mais centros únicos, irradiadores da verdade a ser seguida e aplicada como regra, também não há mais nações com esses pressupostos. As fronteiras nacionais inventadas e fixas, a separar "nós e outros", "ordem e desordem", "cosmos e caos", "verdade e impostura", não mais se sustentam.

As transformações constantes na tecnologia, nas telecomunicações, na forma de trocas e na produção de bens culturais e econômicos acabam por tornar instáveis as identidades fixas, baseadas em noções espaços-temporais de etnia e/ou nação. Para Hall (1997) essa crise de identidade decorre, entre outros fatores, do deslocamento de estruturas e dos processos centrais das sociedades modernas, acrescidas pelo abalo em seu quadro de referências. Temos, então, uma identidade descentrada, deslocada e fragmentada; portanto, mais móvel.

De acordo com Giddens (Apud Hall, 1997: 16), o ritmo acelerado e o alcance global da interconexão das diferentes áreas do planeta trazem como conseqüência transformações sociais globais, tanto no que se refere às noções de tempo e espaço, quanto ao desalojamento do sistema social, marcado pela descontinuidade. Para Laclau (Apud Hall, op.cit.: 17), a contemporaneidade vem caracterizada pela diferença, pelas articulações parciais dos elementos identitários, pelo deslocamento que desarticula as identidades mestras, baseadas na posição de classe, na etnia e na nacionalidade.

Silviano Santiago (1978) trabalha identidade nacional como processo de rearticulações, em que os códigos culturais impostos pelos colonizadores foram transfigurados sistematicamente em suas normas e características, destruindo-lhes a unidade, a pureza e o sinal de superioridade, imprimindo-se neles rasuras e transgressões que resultam em novas configurações. Instaura-se um "entre-lugar" para 
os discursos periféricos, como o latino-americano. Nem a simples negação da influência estrangeira, nem a sua aceitação cega, mas a "apropriação que instaura o espaço da mediação cultural onde a hegemonia vai ser desafiada" (Guelfi, 1996: 140).

Ao se acentuarem os contatos e as trocas entre culturas, acentua-se também o processo de deslocamento das identidades nacionais, colocando em pauta o hibridismo, a transculturação. O local e o global imbricam-se originando articulações novas. O local é penetrado e moldado por influências sociais muito distantes dele, mas, ao mesmo tempo, esse local acaba por transformar o global, numa interação de mão dupla. A difusão do consumismo, real ou imaginado, contribui para esse efeito de "supermercado cultural", desalojando e desvinculando as identidades de tempo e espaços restritos. García Canclini é inovador em sua reflexão sobre identidades, pois as relaciona diretamente com o consumo. Para ele as identidades hoje são definidas e configuradas no consumo, isto é, no acesso que alguém tem, ou que poderia ter, aos bens materiais, estéticos e culturais produzidos. Ocorre, portanto, a redefinição do senso de pertencimento e identidade, "organizado cada vez menos por lealdades locais ou nacionais e mais pela participação em comunidades transnacionais desterritorializadas de consumidores" (García Canclini, 1995: 28).

Cabe, no entanto, acrescentar que esse processo não é homogêneo, mas tem uma clara geometria de poder, abrangendo desigualmente regiões e especialmente estratos da população. Se a possibilidade das diferentes escolhas identitárias é vasta nos centros, nas periferias o ritmo é mais lento e desigual, e o pluralismo se vê restrito pelas condições precárias que não permitem o acesso aos mecanismos de produção dessas diferentes opções identitárias. Outro aspecto a ser destacado é que hoje o impacto global vem associado a um novo interesse pelo local. A formação dessas novas identidades transterritorais e multilingüísticas coexiste com a tentativa de remodelação das culturas nacionais. Na arte, por exemplo, se o processo de desterritorialização existe e ganha amplos espaços, também há fortes movimentos de reterritorializar, afirmando o local, o específico. O processo, ao invés de antagônico, é mais complementar. A hibridação intercultural reconstrói as identidades étnicas, regionais e nacionais, mas não nos mesmos moldes modernos, pois não se pode mais negar a nação como entrecruzamento, nos cenários multideterminados, de uma diversidade de sistemas simbólicos.

$\mathrm{Na}$ produção de identidades persistem os conflitos. Merece cada vez maior destaque as negociações estabelecidas, numa verdadeira co-produção, pois "a identidade é teatro e é política, é representação e ação" e "estudar o modo como estão sendo produzidas as relações de continuidade, ruptura e hibridação entre sistemas locais e globais, tradicionais e ultramodernos, do desenvolvimento cultural é, hoje, um dos maiores desafios para se repensar identidade e a cidadania" (García Canclini, op.cit.: 151-2).

\section{A identidade brasileira pensada e recriada pela MPB}

No Brasil, para pensar a questão das transformações identitárias, parece-me fundamental resgatar o papel dos criadores do que veio a denominar-se Música Popular Brasileira, na formação de uma identidade plural, híbrida, em que se articulam o popular, o massivo e o culto; o próprio e o alheio; o local e o global.

Os criadores da MPB, a partir dos anos 60, auxiliam a criar um novo tipo de relação identitária, uma nova busca de identificação com símbolos e elementos nacionais, sobretudo para a parcela mais jovem da população. A própria denominação encarna esse desejo, afinal, não é impunemente que se chamam Música Popular Brasileira. O que estaria subjacente a esses nomes? Talvez o desejo de deixar bem marcado que estavam falando de um local específico e sentiam-se vinculados ao seu país de origem; e também como resposta aos inúmeros críticos ligados a uma tradição conservadora, que insistiam em afirmar que ambas as propostas eram estrangeirizantes por reproduzirem o som ianque e, pretensamente, renegarem a cultura nacional.

No período em que estava sendo gestada - anos 60 - o governo militar instalado buscou apropriarse dos símbolos pátrios e impingir um nacionalismo xenófobo e truculento. Por outra parte, existia uma elite intelectual tradicional a defender os valores pátrios e defenestrar qualquer tentativa de transformação cultural que não seguisse seus padrões. Contra essas duas posturas, criadores da MPB se insurgiram e entraram na disputa da definição do que era ser brasileiro, propondo-se a rediscutir a identidade nacional em outros moldes.

É interessante perceber que a MPB foi se transformando, no decorrer dos anos, em um dos índices mais fortes da brasilidade e do "orgulho nacional"; um aspecto que, junto com o futebol, tem servido para o reconhecimento interno e também externo da marca do ser brasileiro. Não custa lembrar que os músicos ligados à MPB, desde os anos 60 até hoje, estão inseridos nas discussões sobre identidade e nação. Alguns imbuídos de um nacionalismo mais fechado e reativo; outros de uma noção de identidade em termos mais abertos e menos fixos, como bem o demonstra a proposta tropicalista.

No Brasil dos anos 60 o mundo da cultura passou por um período de intensa criação que interligava as diversas artes. Um dos elementos que possibilitou essa interligação foi a preocupação comum a esses criadores de pensar o Brasil e o seu futuro: "Quem somos? Que projeto de Brasil queremos? Como implantá-lo?" Havia uma confluência ideológica que, a despeito das divergências pontuais - que eram muitas, como comprovam as acirradas discus- 
sões estabelecidas - possibilitou a criação de um ambiente de efervescência criativa nas áreas acadêmicas, no teatro, no cinema, na poesia e na música. O momento parecia propício, mas o golpe militar de 64 representou um baque nas pretensões desses criadores de pensar e transformar o Brasil numa nação mais justa e soberana. Com muito sofrimento, viram-se obrigados a revisar seus projetos. Por outro lado, o golpe militar resultou também num forte elemento aglutinador das esquerdas das várias áreas - política, cultural e artística. $\mathrm{O}$ inimigo comum fez aflorar a necessidade da união, superando as divergências. O ideário em torno da revolução e da nação "todos como um" ganhou força. $\mathrm{O}$ pensamento nacional-popular era hegemônico e sua críti$\mathrm{ca}$, nas artes, somente passou a ter visibilidade a partir da proposta tropicalista, em 67.

Dispostos a dar sua contribuição na revolução que se vislumbrava, os cantores e compositores da MPB se propunham a produzir uma música que, valorizando as conquistas inovadoras e modernas da Bossa Nova, resgatasse os elementos da cultura popular, reafirmando, assim, sua condição de brasileiros e disposição a criar a partir do contexto em que viviam.

A Revista Civilização Brasileira, espaço importante de debate nos anos 60, dispunha-se a pensar o Brasil e reunia em suas páginas análise e discussão de temas que abarcavam questões políticas, ideológicas e sobretudo culturais e artísticas. Bossa Nova, MPB, nacionalismo, "entreguismo", novos rumos, pureza-cópia... eram alguns temas ligados à música que foram discutidos apaixonadamente. Em suas páginas encontramos José Ramos Tinhorão, Ferreira Goulart, Edu Lobo, Capinam e, é claro, Caetano Veloso, entre tantos dispostos a pensar o Brasil e discutir a música popular que aqui se fazia.

$\mathrm{O}$ embate que se estabeleceu entre Tinhorão (estudioso da música popular, com posições conservadoras e ferrenho defensor da "pureza" de uma música com "raízes" brasileiras) e os criadores, defensores e continuadores da Bossa Nova mostrava, por um lado, que a questão nacional e a reflexão sobre a nossa identidade estava na ordem do dia; e, por outro, que as transformações propostas por uma nova geração incluíam o diálogo mais aberto com o estrangeiro, sem demonizá-lo, demonstrando uma visão menos estreita do país e não mais aceitando uma identidade nacional fixa e imutável.

Em 1963, Tinhorão publicou um artigo na revista Senhor (posteriormente reproduzido em seu livro Música Popular - um tema em debate, cujas referências aqui se tomam da edição de 1969) em que, de modo pejorativo, tentava demonstrar que a Bossa Nova (BN) e a nova música popular que se estava criando naquele momento eram fruto de uma americanização de nossa música e que estariam colaborando para a penetração norte-americana na MPB:

Filha de aventuras secretas de apartamento com a música norte-americana - que é, inegavelmente, sua mãe - a bossa nova, no que se refere à paternidade, vive até hoje o mesmo drama de tantas crianças de Copacabana, o bairro em que nasceu: não sabe quem é o pai. (...) Acontece que, de uma hora para outra, a mãe norte-americana da jovem bossa meio-sangue resolveu reconhecê-la publicamente como filha, acenando-lhe com uma herança fabulosa de dólares em direitos autorais. $\mathrm{E}$ foi assim que (...) começaram a aparecer - para desgraça e reputação da mãe da pobre moça - os pais da bossa nova (Tinhorão, 1969: 25).

No mesmo artigo-capítulo, Tinhorão estabelecia uma relação dos pais da BN com a cultura norteamericana, tentando comprovar sua venda "ao capital estrangeiro". Vejam-se alguns exemplos:

JOHNNY ALF, pianista (mulato brasileiro de nome americano, disfarçando o nome verdadeiro: João Alfredo);

ANTÔNIO JOBIM, maestro (compositor repetidamente acusado de apropriar-se de músicas norteamericanas, esconde o nome Antônio sob o apelido americanizado de Tom);

VINÍCIUS DE MORAIS, poeta (velho compositor desconhecido até o advento da bossa nova, já em 1933 conseguia gravar a fox-canção "Dor de uma saudade", imitando o ritmo norte-americano);

JOÃO GILBERTO, violinista (cidadão baiano, conhecido na intimidade por Gibi, de quem chegou a anunciar-se que ia requerer a cidadania norte-americana) (Ibid.: 26).

Por aí se pode ter uma idéia da virulência do embate. Tinhorão falava em nome da parcela mais conservadora da intelectualidade, disposta a preservar um purismo de nossa cultura contra qualquer influência externa, sobretudo norte-americana.

Em debate promovido pela Revista Civilização Brasileira, em 1966, Tinhorão deixava claro que a BN nada mais era do que "um tipo de jazz: a matériaprima era brasileira e a forma norte-americana" (Lobo; Tinhorão et alii: 1966: 307), seguindo a regra geral nas relações entre países desenvolvidos e os menos desenvolvidos. Afirmava a inautenticidade da BN por ela conscientemente "assimilar e incorporar à produção musical ritmos, estilos e harmonias de músicas estrangeiras" (Ibid.: 312).

A Edu Lobo, nessa ocasião, coube responder a tais críticas. Contrapondo-se a Tinhorão, afirmava os ganhos imensos que Tom Jobim, João Gilberto, enfim, a BN, trouxeram para nossa música, confirmando o seu caráter brasileiro. Para confirmar sua tese, citava Mário de Andrade: “A reação contra o que é estrangeiro deve ser feita espertalhosamente pela deformação e adaptação dele, não pela repulsa" (Ibid.: 309), mas imbuído do ideário nacional- 
popular, completava, ainda citando Mário de Andrade: "O artista não deve ser exclusivista, nem unilateral. O compositor brasileiro tem que se basear quer como documentação, quer como inspiração no folclore" (Ibid.). E ele mesmo complementava, afirmando:

Quando se chama de autêntico só o samba, comete-se um equívoco. Dizer que bossa nova sofreu influências do jazz como fator negativo, chega a ser cômico porque então seria preciso lembrar que o samba tem influência africana e chegaríamos ao caos, sem encontrar nenhuma música autêntica. Por que dizer que um é autêntico e outro não? (Ibid.: 312).

Quando o tema é a canção de protesto, que incorporava nas letras a problemática e as lutas ligadas à realidade brasileira, Tinhorão não se dava por vencido e reafirmava seu ponto de vista. Para ele, essa seria uma maneira dos compositores ligados à BN tentar fugir da alienação, pois a fuga "se daria pela letra das composições. Isto é, diante da aberração que consiste em descobrir que se estava falando musicalmente de temas universais, com sotaque americano, o que a chamada participação pretende é falar nacionalisticamente de temas nacionais, mas sem perder o sotaque (Ibid.: 310)". Em outras palavras, questionava: como aceitar uma letra engajada se a música não era nossa?

Ao responder, Edu Lobo novamente acentuou a profunda ligação que os cantores e compositores ligados à MPB do período tinham com os temas nacionais. Apoiando-se uma vez mais em Mário de Andrade, afirmava:

O período atual do Brasil, especialmente nas artes, é o de nacionalização. Estamos procurando conformar a produção surgida no país com a realidade nacional. O critério atual da música brasileira deve ser não filosófico, mas social, deve ser um critério de combate (Ibid.: 311).

As citações de Mário de Andrade feitas por Edu Lobo são um dado importante e demonstram como esse embate era levado a sério. Responde a um nacionalista ortodoxo com um outro nacionalista mais requintado e menos esquemático.

Nesse debate percebem-se nitidamente a presença do ideário nacional-popular. A tradição nacionalpopular tem origem, no Brasil, na segunda fase do movimento modernista - aquela que vai de 1930 a 1945. Para seus seguidores, além de brasileira e moderna, a arte precisaria ser social, isto é, dirigir-se ao povo brasileiro e levar em conta seus problemas. Subjaz neles uma visão de arte enquanto reflexo da realidade e instrumento de conscientização política. Com seus estudos sobre a música brasileira, Mário de Andrade, um dos seus principais representantes, exerceu forte influência em compositores como Villa Lobos e Camargo Guarnieri, nacionalistas ligados à questão popular. José Miguel Wisnik (2001: 134) sintetiza muito bem a conjunção entre o nacional e o popular na arte, apontando que ela "visa à criação de um espaço estratégico onde o projeto de autonomia nacional contém uma posição defensiva contra o avanço da modernidade estética e pelo mercado cultural."

Em nome "da estilização das fontes da cultura popular rural, idealizada como a detentora pura da fisionomia oculta da nação" (Ibid.: 133), o discurso nacionalista do Modernismo renegou a cultura popular emergente dos grandes centros urbanos por temer que esta desorganizaria a "visão centralizada homogênea e paternalista da cultura nacional", pois "rebelde à classificação imediata pelo seu próprio movimento ascendente e pela sua vizinhança invasiva, ameaça entrar por todas as brechas da vida cultural, pondo em xeque a própria concepção de arte do intelectual erudito (Ibid.: 132)."

O que se pretendia era uma elevação "estéticopedagógica do país", incorporando e sublimando a rusticidade do folclore e, ao mesmo tempo, aplacando "através da difusão da cultura alta a agitação urbana (o povo deseducado) a que os meios de massa (...) davam trela" (Ibid.: 134).

Mário de Andrade, assim como Villa-Lobos, propagava a superioridade do folclore. Ele, como afirma Wisnik, penetrava nos processos "mitopoéticosmusicais" da cultura popular, mas com um crivo crítico, deslocando, relativizando e reorganizando tais elementos a partir de sua formação erudita, superando assim um nacionalismo ortodoxo e programático. Mário via na música rural, marcadamente de origem nordestina, virtudes "autóctones" e "tradicionalmente nacionais". Ele não renegava toda produção cultural urbana, valorizava aquela parcela que conseguia manter-se aparte da influência "deletéria do urbanismo", trazida pelo progresso e pelo internacionalismo. Para isso, seria preciso:

(...) ao estudioso discernir no folclore urbano o que é virtualmente autóctone, o que é tradicionalmente nacional, o que é essencialmente popular enfim, do que é popularesco, feito à feição do popular, ou influenciado pelas modas internacionais (Andrade, 1962: 167)

Se nacional-popular versus vanguarda-mercado já era um embate incisivo nas artes modernistas de 30 e 40, sobretudo com Villa-Lobos e Mário de Andrade, esse embate vai se aprofundar, tornandose mais decisivo e explosivo na criação artística da década de 60, sobretudo na MPB que se configurava. Como se percebe, Mário de Andrade era uma das fontes teóricas preferenciais e a citação feita por Edu Lobo não foi casual. Assim como Mário, que afirmava que a música popular era nossa criação 
mais forte e bela, percebia-se entre os criadores de arte e cultura nos anos 60 que a música popular no Brasil ocupava um lugar privilegiado e que ela poderia contribuir decisivamente para as transformações sociais tão necessárias para o país.

Com o advento da ditadura e todos os problemas conseqüentes, no seio da Bossa Nova operaram-se transformações. Houve uma paralisação da pesquisa musical em níveis formais e uma ênfase nas letras. O conteúdo semântico passou a ter uma importância fundamental diante da realidade que o país passava a viver. A linguagem se tornou agressiva, abordando diretamente o problema do subdesenvolvimento ou, em tom de lamento, expondo as condições subumanas, sobretudo dos nordestinos e dos habitantes dos morros.

Carlos Lyra foi um dos responsáveis por essa mudança de rumos, articulando uma reaproximação da música popular brasileira com a cultura popular, esforço semelhante ao feito por Vianinha, no teatro, e Ferreira Gullar, na poesia. Carlos Lyra (Apud Homem de Mello, 1976: 114), analisando o período, afirma:

Nessas buscas da realidade nacional acabei encontrando tanto o Villa-Lobos como o Nélson Cavaquinho, Cartola, João do Vale, os verdadeiros valores nacionais [grifo nosso]. E o negócio era ir às escolas de samba e ver qual era a realidade nacional em todos os seus aspectos. Eu procurava mesmo esse pessoal de escola de samba e também os caras que tinham leitura, como Vandré.

A politização e as pesquisas que, na música, resgatavam o regionalismo, especialmente do nordeste e suas tradições, apresentavam similitude com a criação dos Centros Populares de Cultura - CPC, articulados pela UNE, com ênfase na arte engajada. A música popular deveria ajudar a resgatar os valores mais "genuínos" da nacionalidade e auxiliar na sedimentação de uma cultura nacional. A canção deveria ter uma função muito mais política que estética, seria um instrumento de conscientização, denunciando a realidade injusta em que vivia a maioria da população e fomentando a conscientização e a mobilização do povo. Em nome da defesa da pátria brasileira e de sua cultura, a incorporação na arte seja na música, no teatro ou na poesia - de elementos estranhos à cultura nacional, naquele momento, era considerada por alguns nacionalistas mais ortodoxos como "traição à pátria".

Heloísa Buarque de Hollanda (1992) aponta que no projeto dos CPCs - que propunha uma arte engajada nos moldes do nacional-popular - a palavra poética deveria ter uma eficácia revolucionária, vista enquanto instrumento de tomada de poder. Engajamento cultural e militância política estavam intrinsecamente ligados. No manifesto do CPC, de março de 1962, isto aparece claramente: "O artista que pratica sua arte situando seu pensamento e sua atitude criadora exclusivamente em função da própria arte é apenas a pobre vítima de um logro tanto histórico quanto existencial" (Apud Buarque de Hollanda, 1992: 122).

No plano musical, resgatavam-se as velhas formas da canção urbana (sambão, sambinha, marcha, marcha-rancho...) e rural (moda de viola, samba de roda, desafio...), atendo-se à simplicidade formal. $\mathrm{O}$ importante era o conteúdo a ser transmitido, como muito bem sintetiza Geraldo Vandré:

Acho que em canção popular a música deve ser uma funcionária despudorada do texto. Isso não quer dizer que não se deva usar os recursos artesanais, com a maior disponibilidade possível, para o desenvolvimento de uma ideologia musical nacional. Mas é preciso ter um cuidado muito grande para que o uso desses recursos esteja realmente a serviço do texto, que é fundamental na canção popular (Homem de Mello, 1976: 128).

Carlos Zílio (1983) criticava essa postura, pois via na arte nacional-popular uma tendência ao mimetismo com o popular. Advertia que, para preservar os valores nacionais, "ameaçados pela cultura norte-americana", os seguidores da concepção nacional-popular reverenciavam a arte popular como a única realmente brasileira, que precisava ser protegida para não se contaminar. Zílio via nesta proposta um caráter restritivo, pois ela subestimava "as profundas interações dialéticas entre o nacional e o internacional", uma vez que continha "uma visão preconcebida do particular da nossa cultura" (Zílio, 1983: 47).

Caetano Veloso não se eximiu desse debate, aliás, como nunca se eximiu de debate algum. Posicionarse frente a questões ligadas ao Brasil, nossa identidade, de onde viemos e para onde vamos são freqüentes no decorrer da carreira de Caetano, seja em entrevistas, artigos, livro (Verdade Tropical o comprova) e também num grande número de suas composições. Mesmo antes da Tropicália, momento fundamental nesse debate, ele tomava posição, fomentando a discussão. Nas páginas da Revista Civilização Brasileira, em 1966, encontramo-lo entre Capinam, Ferreira Gullar, Gustavo Dahl, Nara Leão, Flávio Macedo Soares e Nelson Lins e Barros debatendo: "Que caminho seguir na música popular brasileira?" O próprio título já era emblemático e marcava a hegemonia que a linha nacional-popular tinha dentro da canção popular naquele momento, afinal, sugere-se a busca de "um caminho" e não de "caminhos". Caetano já aí demonstrou seu descontentamento e conseguiu dar um passo adiante no debate, criticando tanto a postura assumida por Tinhorão, quanto a postura assumida então pela maior parcela de cantores e compositores da canção popular. 
Caetano foi enfático ao colocar em questão uma visão nacionalista que via como retrógrada para a MPB:

A questão da música popular brasileira vem sendo posta ultimamente em termos de fidelidade e comunicação com o povo brasileiro. Quer dizer: sempre se discute se o importante é ter uma visão ideológica dos problemas brasileiros, e a música é boa, desde que exponha bem essa visão; ou se devemos retomar ou apenas aceitar a música primitiva brasileira (Caetano, apud Veloso, Gullar et alii, 1966: 378).

Essas duas visões seriam empobrecedoras ao colocar uma camisa de força na criação, com limites rígidos, os quais ele rejeitava. De um lado Tinhorão, que defendia "a preservação do analfabetismo como única salvação", de outro aqueles que resistiam "a esse tradicionalismo com uma modernidade de idéia ou de forma imposta como melhoramento qualitativo" (Ibid.: 378). Para Caetano, "a música brasileira se moderniza e continua brasileira", não devendo ficar atrelada a padrões fixos, pois "toda informação é aproveitada (e entendida) da vivência e da compreensão da realidade cultural brasileira" (Ibid.). Nota-se sua insistência no permanecer brasileira e ser feita a partir de nossa realidade, mas renovandose e abrindo-se a novos caminhos. Não renegava a tradição, ao contrário, a reafirmava: "Se temos uma tradição e queremos fazer algo de novo dentro dela, não só teremos de senti-la, mas conhecê-la. E é este conhecimento que vai nos dar a possibilidade de criar algo novo e coerente com ela" (Ibid.).

A necessidade da "retomada da linha evolutiva" dentro da MPB seria capaz de dar organicidade para "selecionar e ter um julgamento de criação", uma organicidade entendida como estruturação que possibilitasse "o trabalho em conjunto, inter-relacionando as artes e os ramos intelectuais" (Ibid.). João Gilberto seria o parâmetro: "a informação da modernidade musical utilizada na recriação, na renovação, no dar um passo à frente da música popular brasileira" (Ibid.), conjugando tradição e modernidade. Ficam claros aqui alguns pressupostos que, no ano seguinte, estariam na base da Tropicália. Também nesse debate Caetano deixava claro o que o movia na criação naquele momento:

Sei também que a Arte não salva nada nem ninguém, mas que é uma das nossas faces. Me interessa que corresponda o que faço à posição tomada por mim diante da realidade brasileira. Por mim e por todos os moços da classe média, que estudam nas faculdades e se interessam em lutar contra a alienação (Ibid.: 384).

Ferreira Gullar, imbuído do espírito nacional-popular, encerrou esse debate propondo a luta contra a cultura de massa internacional que traria malefícios à cultura brasileira, citando nominalmente o "Iê-iêiê". Já que não se podia fechar o país para essa cultura de massa internacional, devia-se combatê-la culturalmente. A forma de combate - resguardar nossas raízes: "fazer com que os compositores procurem dentro da própria cultura brasileira, nos elementos populares da música brasileira, a fonte de uma nova criação que possa realmente fazer frente a essa onda internacional" (Ibid.: 384-385). Por fim, na mesma forma como Mário de Andrade décadas anteriores havia feito, Gullar reafirmava o poder da música popular no Brasil: "Das formas de arte brasileira é a música talvez a que esteja mais entranhada no meio do povo brasileiro; é a que tem mais força, mais capacidade de enfrentar a influência estrangeira" (Ibid.: 385). Em poucas palavras Gullar sintetizava o pensamento hegemônico nas artes do período, propondo o uso da arte para vencer o inimigo capitalista, que, em sua ânsia de expansão, progresso e desenvolvimento, devorava nesse processo todas as tradições populares. Gullar, como deixa claro em texto posterior (1979), pretendia contrapor-se ao "vanguardismo formalista", cuja concepção de arte via como elitista e hermética, dominada pela importação de formas. Esse autor não negava a importância e a influência na arte nacional da arte estrangeira. Ressaltava, contudo, que em países cujas culturas não eram consistentes e estavam em formação, as influências externas tendiam a ser "maléficas", agindo como fator de perturbação do processo formativo da cultura nacional.

Esse debate promovido pela Civilização Brasileira deixou claro o que viria a seguir. Desde de 1964 se percebiam rupturas com a proposta então hegemônica dentro da MPB. O caminho único de uma arte nacional-popular não respondia mais aos anseios de todos os seus criadores e muito menos aos da sociedade que entendiam representar. Caetano, nesse debate, explicitava-as e já apresentava alguns traços do que viria a ser a Tropicália; Gullar fincava o pé na defesa do nacional-popular. As cartas novamente estavam dadas, o embate estava apenas começando.

Em 1967, a trupe tropicalista, tendo Caetano e Gil à frente, ateou fogo à discussão, trazendo novas cartas na manga: Oswald de Andrade e a antropofagia, a produção considerada brega, kitsch da música brasileira e, o que causou o mal-estar maior, o diálogo com o pop-rock inglês dos Beatles, com suas guitarras elétricas e, conseqüentemente, o diálogo com o "Iê-iê-iê" nacional, aproximando-se da Jovem Guarda.

Antes dos tropicalistas, o artista plástico Hélio Oiticica (ver Zílio, 1983) já afirmava que vivíamos numa realidade marcada por contradições, e que a arte devia reconhecer esse fato e agir a partir dele, afinal o Brasil ainda não teria um sistema de arte estruturado e sofria as mais diversas influências: modismo, modelos externos, diversidades regionais. 
Fugir do consumo seria alienar-se; numa visão antropofágica, afirmava que precisávamos "consumir o consumo". Para superar o caráter subdesenvolvido da nossa arte, tornava-se necessário primeiro reconhecer esse caráter.

A arte baseada nos pressupostos do nacional-popular se viu questionada nas artes plásticas pela antiarte de Oiticica e Vergara; no teatro, pela ousadia formal e inquietante de José Celso Martinez; no cinema, por Glauber Rocha e seus transes oníricos, questionando o papel dos intelectuais e mostrando uma visão de Brasil complexa. Formava-se

\section{(...) uma geração sensibilizada pelo desejo de fazer da arte não mais o instrumento repetitivo e previsível de uma veiculação política direta, mas um espaço aberto à invenção, à provoca- ção, à procura de novas possibilidades expres- sivas, culturais, existenciais (Buarque de Hollanda, 1992: 65).}

Mas se esse tipo de crítica já existia no campo das artes e da cultura, ela passou a ter maior visibilidade quando trazida para o campo da música popular, cuja abrangência e penetração eram muito maiores. A Tropicália, além da inovação estético-musical, veio repensar a questão nacional, o Brasil e sua identidade em outros parâmetros. Assumiu uma postura contra um nacionalismo fechado e ressentido, afirmando a necessidade do diálogo e da abertura para o mundo, para a "temida" cultura estrangeira, pois via nesse contato a possibilidade de crescermos e nos firmarmos como nação. Isso fica claro em muitas análises feitas por Caetano. Em entrevista concedida a Christopher Dunn (1994) afirmava que a Tropicália:

(...) foi uma crítica ao tipo de nacionalismo que nos parecia ingênuo e defensivo. Nós acreditávamos ambiciosamente que, pelo menos do ponto de vista da música popular, podíamos e devíamos ser agressivos, ter um nacionalismo agressivo (Caetano apud Dunn, 1994: 101).

Os tropicalistas apropriaram-se e fizeram a sua leitura da antropofagia cultural de Oswald de Andrade "em que você come tudo o que vem de qualquer lugar do mundo e faz daquilo o que você quer, digere como quer. É uma idéia de comer tudo o que houver e produzir uma coisa nova (Ibid.)."

Na linha de Oswald, a Tropicália, no dizer de Caetano, propunha uma mente que não fosse "prisioneira das consciências enlatadas", criando "uma arte, um jeito de ser, um jeito de conviver que não [deixasse] o enlatado dominar", mas não da forma defensiva e programática de um nacionalismo que levaria à provincialização, com uma cultura fechada que parecia "não ter força própria" e preferia "viver da força negativa, que é uma reação à força do outro" (Ibid.: 105).
A Tropicália queria afirmar o próprio, mas não se fechando para o estrangeiro, e sim o devorando e transformando-o com crivos locais, reafirmando assim a identidade brasileira como diferenciada:

A Bossa Nova tinha justamente uma grande afirmação da cultura brasileira porque não tinha tido problemas em assimilar a influência da melhor música norte-americana. (...) Eles [João Gilberto e Tom Jobim] não se sentiram humilhados, se sentiram estimulados. Nós também preferimos nos sentir estimulados por todas as referências. (...) Criamos um estilo de liberdade, porque a gente não se sentia humilhado pela presença da cultura dos países mais ricos do que nós (Ibid.: 102; 104).

Do cenário local, os tropicalistas se apropriaram de um tipo de música considerada brega e desqualificada (Vicente Celestino, Carmem Miranda, as irmãs Batista, Isaurinha Garcia...) e a deslocaram ironicamente, colocando-a em um "ambiente de repertório elevado", como afirma Caetano, acatando-a como produtos de uma cultura nacional que também compunha nossa brasilidade. Enfim, propunham "uma postura de estar-no-mundo (...), não como um país de Terceiro Mundo que fica ao reboque do que acontece nos países mais desenvolvidos", mas sim de "eu vivo no mundo hoje e faço com os elementos de que disponho esta arte, este gesto" (Ibid.: 100). Por um lado, essa postura contradizia Mário de Andrade à medida que dialogava também com o "popularesco feito à feição do popular, ou influenciado pelas modas internacionais" (Andrade, 1962: 167), atitude rejeitada pelo modernista. Mas, por outro, os tropicalistas utilizavam o procedimento sugerido pelo Mário: extrair da música popular o que ela tinha de melhor, dando-lhe um teor mais erudito e moderno; e devolver às massas o seu "populário sonoro" convertido em "música artística", tendo em vista a afirmação da brasilidade. Uma brasilidade, porém, não baseada no consenso, no ideário do "todos como um", mas no dissenso de uma nação que são muitas, de um Brasil formado por culturas diversas, não mais querendo forçar uma igualdade utópica construída a partir de padrões que estabeleciam o "bem" a ser seguido e valorizado, demonizando o restante como cópia, lixo cultural, o não-Brasil. Uma brasilidade aberta e construída no diálogo e no embate, não fixa e imutável.

$\mathrm{O}$ caminho aberto pelos tropicalistas aliado às transformações pelas quais passou o país e o mundo sob a égide da globalização, assim como toda a rediscussão estabelecida sobre nação e identidade em termos teóricos e práticos, possibilitaram o advento de novos parâmetros de discussão que a música brasileira hoje está percorrendo. O Movimento Manguebeat, o Movimento Hip Hop, o Funk se apresentam, e o processo continua. mfamecos 


\section{REFERÊNCIAS}

ANDERSON, Benedict. Nação e consciência nacional. São Paulo: Ática, 1989.

ANDRADE, Mário. Ensaio sobre a música brasileira. São Paulo: Martins, 1962.

BUARQUE DE HOLLANDA, Heloísa. Impressões de viagem: CPC, vanguarda e desbunde: 1960 / 70. Rio de Janeiro: Rocco, 1992.

DUNN, Christopher. "Caetano Veloso: Tropicalismo revisitado." Revista de literatura Brasileira- Journal of Brazilian Literature, n.11, ano 7, 1994, Porto Alegre. p. 99-110 (Entrevista concedida por Caetano Veloso a Christopher Dunn em 07/07/1992).

GARCÍA CANCLINI, Néstor. Consumidores e cidadãos: conflitos multiculturais da globalização. Rio de Janeiro: Editora UFRJ, 1995.

GUELFI, Maria Lúcia Fernandes. "Identidade cultural numa perspectiva pós-moderna." Revista Gragoatá, Niterói: EDUFF, n.1, p-137-149, 2.sem.1996.

GULLAR, Ferreira. "Vanguardismo e cultura popular no Brasil". Temas de Ciências Humanas, São Paulo, v.5, p.75-93, 1979.

HALL, Stuart. Identidades culturais na pósmodernidade. Rio de Janeiro: DP\&A, 1997.

HOMEM DE MELLO, Zuza. Música popular brasileira. São Paulo: Melhoramentos, Editora da Universidade de São Paulo, 1976.

LOBO, Edu; TINHORÃO, J.R. et al. "Confronto: Música Popular Brasileira." Revista Civilização Brasileira, n.3, ano I, julho 1965. p. 305-312.

NERCOLINI, Marildo José. A construção cultural pelas metáforas: $A$ MPB e o Rock Nacional Argentino repensam as fronteiras globalizadas. Rio de Janeiro: UFRJ/ LETRAS, 2005. (Tese defendida no Programa de Ciência da Literatura.)

SANTIAGO, Silviano. "O entre-lugar do discurso latino-americano." In: _- Uma literatura nos trópicos: ensaios sobre a dependência cultural. São Paulo: Perspectiva, 1978. p.11-28.

TINHORÃO, José Ramos. Música popular: um tema em debate. 2ed. Rio de Janeiro: JCM, [1969].
VELOSO, Caetano; GULLAR, Ferreira; et alli . "Que caminho seguir na música popular brasileira?" Revista Civilização Brasileira, n.7, ano I, maio de 1966. p. 375-385.

WISNIK, José Miguel. "Nacionalismo Musical." In: SQUEFF, E. e WISNIK, Miguel. O Nacional e o Popular na Cultura Brasileira - Música. São Paulo: Brasiliense, 2001.

ZÍLIO, Carlos. "Da antropofagia à tropicália." In: ZÍLIO, C., LAFETÁ, J., CHIAPPINI, L.M. O nacional e o popular na cultura brasileira - Artes Plásticas e Literatura. São Paulo: Brasiliense, 1983. 2ed. p.11- 56. 